\title{
VIDA I IMPORTÀNCIA DE RAMON LLULL EN EL CONTEXT DEL SEGLE XIII
}

\author{
J.N. HILLGARTH \\ Pontifical Institute of Mediaeval Studies \\ (Toronto, Canadá)
}

Per al Pare Miquel Batllori, amb l'admiració de sempre

En el seu llibre Western Views of Islam, Sir Richard Southern va nomenar el segle XIII como l'era de l'optimisme'. Aquest optimisme podia haver semblat totalment justificat per als contemporanis. Aquesta va ser una època que va experimentar l'apogeu del poder papal medieval -el qual havia finalment vençut el Sant Imperi Romà-, la creació d'ordes mendicants, el creixement de les universitats i la construcció de nous i millors sistemes de teologia i dret canònic. També es va viure l'avanç del cristianisme llatí amb les armes, tant a l'est (des de Constantinoble fins al Bàltic) com a l'oest, amb la conquesta cristiana de gairebé tota l'Espanya islàmica; en menys de 25 anys, des de 1226 fins a 1248, les possessions musulmanes, que havien constituït una tercera part de la Península Ibèrica, van ser reduïdes al petit regne de Granada. Per a Ramon Llull les conqestes més importants van ser les de Jaume I d'Aragó. Cap al 1245, quan Llull tenia tretze anys, Jaume I havia conquerit les Illes Balears i el regne de València. Com en tota la resta d'Espanya, la població de la Corona d'Aragó, i especialment la d'aquelles regions conquerides, estava barrejada. Mentre que un gran nombre d'immi1962.

'R. W. SOUTHERN, Western Views of Islam in the Middle Ages, Cambridge, Mass,.

"Anuario de Estudios Medievales", 26 (1996) 
grants cristians s'havia assentat a les Illes Balears, molts musulmans (que ara eren esclaus) hi van romandre. A València, la població musulmana, formada per artesans, pagesos independents o parcers, va continuar superpoblant els assentaments cristians. A tota la Corona d'Aragó, i sobretot a les grans ciutats de Barcelona, València i Mallorca, hi havia importants comunitats jueves. La proporció de musulmans i jueus respecte dels cristians era molt més alta que al regne de Castella. A la Corona d'Aragó els no-cristians probablement constituïen més d'una quarta part del total, és a dir, més de 250.000 d'un total d'uns $900.000^{2}$.

Tant els jueus com els musulmans gaudien de la protecció reial, per bé que aquesta protecció no es concedia desinteressadament. Essent comunitats subjugades sense cap dret, llevat d'aquells atorgats per la Corona, els jueus i els musulmans eren -com molt encertadament expressa el títol del llibre de John Boswell sobre el segle XIV - "el tresor reial", el qual el rei podia controlar amb una relativa llibertat $i$ on tenia molts interessos a protegir en front de l'Esglesia i de la població cristiana ${ }^{3}$.

La Corona d'Aragó no va poder expandir-se per terra perquè li ho impedí el gran auge demogràfic i polític dels seus veïns més immediats, França al nord i Castella a l'oest. Tan sols podia fer-ho per mar. Aquesta expansió es va evidenciar en el comerç amb Africa del nord i amb Egipte i, posteriorment, amb les conquestes de Sicília (el 1282), Sardenya (el 1323), i el sud d'Itàlia (el segle XV). La vida de Ramon Llull, amb els seus continus viatges per la Mediterrània, i especialment amb les missions de l'Africa del nord musulmà, hagués estat inconcebible un segle abans. Dins d'una escala individual, Llull representa l'expansió del nou i confiat cristianisme occidental del seu temps. Però representa també els interrogants que apareixen a la darrera part de segle XIII dins el cristianisme respecte de les direccions a prendre. Mentre el segle avançava, els problemes de les Croades eren més evidents. El 1261, Constantinoble va ser recuperada pels bizantins. La derrota de dues Croades encapçalades pel sant rei de França Luis IX, semblaven encara un argument més eficaç. Darrera d'aquella barrera aparentment infranquejable de l'Islam habitaven els mongols els quals, cap al 1250, dominaren la Xina i l'Asia Central, controlaren Rússia

${ }^{2} \mathrm{~J}$. N. Hillgarth, Los reinos hispánicos, 1250-1516, I, Barcelona, 1979, p. 51.

${ }^{3}$ John Boswell, The Royal Treasure: Muslim Communities under the Crown of Aragon in the fourteenth century, New Haven, 1977. 
i havien emprès una sèrie d'atacs devastadors a l'Europa Central. Dins l'Europa occidental el cristianisme llatí estava inquiet a conseqüència dels moviments dissidents i, com a reacció, havia format una Croada armada al sud de França i creat la Inquisició papal. A un nivell menys popular, hi havia força ansietat respecte de la manera com s'havia d'interpretar el nou llegat d'Aristòtil recentment recuperat, si serviria per ajudar o per a minar la doctrina cristiana. Alguns pensadors de considerable importània estaven preocupats per la creixent legalitat i burocràcria dins l'Església i la seva tendència a ofegar la vida espiritual. Totes aquestes causes d'ansietat derivades de les amenaces externes $\mathrm{i}$ internes a la cristiandat llatina es refecteixen - juntament a un optimisme inicial- a la vida de Ramon Llull $i$ als seus escrits sobre les missions, les croades, el perill de l'aristotelisme radical a París, i a la seva continua campanya contra la mundanitat i la corrupció a l'Església.

És important no considerar Llull - com de vegades s'ha fet- un excèntric solitari, menys encara com un creient de qualsevol tipus d'utopia ${ }^{4}$. Ben al contrari, Llull tenia absolut coneixement dels canvis dins la política papal i dels desenvolupaments més importants dins les dues grans ordes mendicants, els dominics i els franciscans ${ }^{5}$. Innocent IV (1243-1254) va ser el primer papa que va combinar la teoria legal dels no-cristians amb la temptativa de convertir als mongols, els quals estaven amenaçant l'existència del cristianisme i de l'Islam. L'impuls que hi havia darrera les accions d'Innocent estava plasmat a la Butlla de Gregori IX, del 1235, que reflectia el pensament apocalíptic de Sant Francesc i dels primers franciscans. "Ara que l'hora onzena ha arrivat", començava la Butlla, "l'home espiritual deu anar a buscar a tots els homes". Mentre que la conversió podia ser només voluntària, era obligació dels cristians predicar l'Evangeli a tothom. Innocent va proclamar que ell no interferiria amb els prínceps musulmans si aquests no impedien l'entrada dels missioners cristians a llurs terres. La croada estava subordinada a la missió espiritual de l'Església. L'esperança que la conversió dels no-cristians era factible es va basar en la convicció de que tots els homes, essent criatures racionals, podien ser convençudes mitjancant arguments racionals. Aquests haurien de dirigir-se, en primer lloc, als

\footnotetext{
${ }^{4} \mathrm{~J}$. N. HILlgaRTH, Raymond Lulle et l'utopie, "Estudios Lulianos", XXV (181-83), pp. 175-85.

${ }^{5}$ Vegeu James Muldoon, Popes, Lawyers, and Infidels, the Church and the nonChristian World, 1250-1550, Philadelphia, 1979.
} 
prínceps no-cristians, tant si eren mongols com musulmans. Al llarg del segle XIII hi va haver esperances que aquests prínceps estaven a punt de convertir-se, i amb ells, convertir als seus súbdits.

Per als pensadors cristians del segle XIII, l'Islam es va presentar com el desafiament més gran (i, en conseqüència, la millor oportunitat). Les comunitats jueves dins l'Europa occidental semblaven un assumpte molt menys urgent. Sant Pau havia predit (Romans, 11:25) que la conversió dels jueus seguiria a la dels gentils. Per tant, l'atenció de la cristiandat llatina estava concentrada en l'Islam.

Aquestes consideracions generals es reflecteixen en el pensament $\mathrm{i}$ les accions de Ramon Llull. La visió de Llull sobre les missions i les croades, de vegades vista com inconsistent i contradictòria ${ }^{6}$, és intel-ligible dins l'estructura general de la política papal ${ }^{7}$. Per a una persona com Llull, que va créixer a Mallorca, una illa sols conquerida per l'Islam el 1229, dos anys abans del seu naixement, amb musulmans convivint al seu voltant com també al altre costat del Mediterrani, l'Islam deu haver estat, des del principi, un fet dominant en la seva consciència. Aquest tret explica la seva decisió, quan va passar d'una vida mundana a una devota a la dècada del 1260 , de concentrar-se més en l'aprenentatge de l'àrab que no pas al de l'hebreu, i de dedicar molta més atenció a l'Islam que al judaisme en les seves obres polèmices. Les idees de Llull difereixen, com podrem veure, de la política papal oficial i també de les dels principals pensadors mendicants, però, en termes generals, hi havia un acord amb ells. La convergència explícita i la interdependència de l'obra missional i la croada en les darreres obres de Llull també apareix en el pensament papal i mendicant. El gran dominicà Ramon de Penyafort, qui va precedir Llull en l'organització d'escoles per a ensenyar l'àrab i l'hebreu als missioners, també predicava la croada. El franciscà Roger Bacon, mentre advocava per l'ensenyament de diverses llengües als missioners, no va descartar una croada a Terra Santa. És important tenir en compte que si bé Llull de vegades escriu sobre les missions sense mencionar les croades, mai parla d'aquestes sense mostrar-se partidari de les missions. Totes dues tasques estan clarament relacionades,

\footnotetext{
${ }^{6}$ Vegeu Benjamin Z. KEDAR, Crusade and Mission, European Approaches towards the Muslims, Princeton, N.J., 1984.

${ }^{7}$ Vegeu Pamela M. BEATTIE, Evangelization, Reform and Eschatology: Mission and Crusade in the Thought of Ramon Llull, tesi doctoral, Univeritat de Toronto, 1995.
} 
però el mètode apostòlic d'evangelització mitjançant la predicació i el martiri és preferible i té prioritat.

La principal diferència entre Ramon Llull i els escolàstics del seu temps, inclosos Bacon i Tomàs d'Aquino, estriba en la seva educació a Mallorca i en la seva decisió (suggerida per Ramon de Penyafort) d'aprendre àrab allí i no, com ell pretenia, estudiar a París, la qual cosa va significar que Llull redactés obres importants en català i no en llatí i que estiguessin, en general, imbuïdes de la influència de l'àrab.

L'educació a Mallorca va tenir encara més conseqüències. L'illa, amb el seu excel·lent port a mig camí ente Espanya i l'Àfrica del nord, i també sobre la ruta natural des de Gènova, al nord d'Itàlia, fins al sud d'Espanya, era el perfecte punt de partida per a un missioner que desitjava viatjar a les corts papals i reials d'Europa i de l'Àfrica del nord musulmà. Molts musulmans encara vivien a Mallorca, la majoria d'ells com esclaus (hi ha documents que demostren que - com molts dels colonitzadors cristians-, tant Llull com el seu pare tenien esclaus musulmans) ${ }^{8}$. Molts d'aquests musulmans eren descendents dels cristians locals que havien estat forçats a convertir-se a l'Islam al segle XII. La seva fe musulmana no devia haver estat molt forta. Aquest fet ens ajuda a entendre com Llull, educat entre musulmans, podria sentir que les seves creences religioses podien canviar-se simplement amb un raonament. Igual que Ramon de Penyafort, Llull va començar les seves activitats missioneres en una terra governada per cristians que gairebé no tenien una oposició intel lectual ni política a la qual fer front. Això contribueix molt més al seu optimisme inicial que, d'altra banda, podria semblar tan sorprenent pel que fa a la possible conversió dels musulmans en general.

Un altre element de l'educació de Llull que ens ajuda a explicar la confiança en la seva obra missionera és el seu status social. Mentre la seva posició precisa a la casa reial del futur rei Jaume II de Mallorca no està definida, ell havia prestat un servei real i aquest fet facilitaria el seu primer (i quasi l'únic) assoliment no literari: la fundació a Mallorca, el 1275-1276, d'una escola per als missioners franciscans. Malauradament, la baralla i la subsegüent guerra entre Jaume II i el seu germà gran, Pere III d'Aragó, van

\footnotetext{
${ }^{8}$ J.N. HILlgaRTH, Ramon Lull's Early Years: New Documents, "Mediaeval Studies", LIII (1991), pp. 337-43.
} 
ser els fets responsables no tan sols del fracàs d'aquesta escola sinó també de molts dels altres problemes de Llull.

Llull va combinar d'una forma extraordinària elements tant de l'orde dominicà com de l'orde franciscà. La seva insistència en la preparació intel-lectual, en la fundació d'escoles per a ensenyar als missioners les llengues que necessitaven per a adreçar-se als musulmans, als jueus $i$ als cristians cismàtics (a l'est), i així també en les disputes públiques adequadament preparades entre els catòlics i altres, prové de Ramon de Penyafort. D'altra banda, la insistència de Llull en què els missioners havien d'estar preparats par al martiri i el seu propi misticisme - formalment influenciat pel sufisme musulmà- prové de les idees franciscanes. Els dubtes de Llull entre les dues ordes s'explica gràcies als deutes que n'havia contret - no és totalment cert que esdevingués un terciari franciscà, malgrat haver estat enterrat a Mallorca en una església franciscana i que estigués en contacte amb els franciscans que més endavant rebrien el nom d'"espirituals".

Encara que Llull ha de ser comprès dins el context general del pensament papal i mendicant, en alguns aspectes, roman independent. Per a ell l'assumpte mongol era més urgent del que semblava als papes del seu temps. Per exemple, el 1309 va escriure:

Hi ha tres emperadors [dels mongols] que, si bé només feia menys de 80 anys que havien baixat de les muntanyes, ara governen més terra que els cristians i els musulmans junts. Un d'aquests emperadors, el senyor de Pèrsia, amb tot el seu exèrcit, s’havia convertit musulmà i així podia impedir la conquesta de Terra Santa. El papa deuria afanyar-se en enviar frares ben preparats abans de que aquest es convertira totalment a la fe musulmana ... També és probable que els altres dos emperadors es convertiran [a l'Islam]. Els mongols podrien conquerir fàcilment Constantinoble i des d'allí avançar cap a'oest.

En el mateix llibre (De acquisitione Terrae Sanctae) i abans, més detalladament, Llull va proposar un mètode pràctic

per a negociar amb els mongols. No hi ha cap dubte que Llull hi va demostrar més agudesa que molts dels seus contemporanis?.

Mentre que Llull mai va poder negociar personalment amb els mongols, repetidament ho va fer amb els musulmans, no tan sols a Mallorca

\footnotetext{
${ }^{9}$ Per edicions de Llull, Liber de acquisitione Terrae Sanctae, vegeu Antoni BoNNER, Obres selectes de Ramon Llull (1232-1316), II, Mallorca, 1989, p. 573.
} 
sinó també en les tres llargues missions al nord d'Africa, en una de les quals va ser empresonat i quasi assassinat. Va predicar, així mateix, a la colònia musulmana prop de Nàpols i hi va visitar els presoners musulmans (sembla que ha estat l'únic missioner cristià que va parlar amb aquesta gent) ${ }^{10}$. L'any 1299 va obtenir permís per a predicar a les mesquites i sinagogues de la Corona d'Aragó i el 1301 als musulmans de Xipre.

Aquí, considero que cal introduir una petita però necessària disgressió. La pràctica reial de forçar els no-cristians a assistir als sermons cristians - que bé eren predicats per Llull o, més sovint, per frares dominics i franciscans - està ja documentada a la Corona d'Aragó a la dècada del 1240. Generalment autoritzada pel papat l'any 1278, aquesta pràctica també apareix a França i a Anglaterra. Els erudits moderns que critiquen Llull -o altres figures del segle XIII, com Ramon de Penyafort- pensen que aquestes pràctiques són ofensives, perquè entren en conflicte amb la tolerància absoluta que ens adherim avui $-\mathrm{o}$ a la que es suposa que ens adherim- ja que s'aprofiten de les avantatges que proporcionen una assistència forçada dels no-cristians als sermons; com també de les obligades disputes i de l'educació forçada dels no-cristians a les escoles cristianes. Aquest és un punt de vista anacrònic pel que fa al passat. No és possible cap acostament imparcial per a algú convençut de les següents tres proposicions: que la veritat absoluta existeix; que es preserva en la (nostra) tradició; i que qualsevol ésser racional, amb clars raonaments al seu favor, deu aceptar-los, a no ser que actuï amb malícia. A l'Edat Mitjana, qualsevol cristià, musulmà o jueu que hagués reflexionat sobre aquesta qüestió, hauria aceptat aquestes proposicions. Cap partidari convençut de qualsevol d'aquestes religions podria haver-se format un concepte de la tolerància absoluta. Allò que era important per a ells, atès que posseïen la veritat, era posar-la a disposició de tothom. Qualsevol forma de fer-ho era legítima, la qual cosa no significa que distintes maneres d'abordar el problema no existissin. La Disputa a Barcelona del 1263 entre els cristians i els jueus, organitzada per Ramon de Penyafort, era molt diferent als procediments a París a la dècada del 1240. Segons les paraules del jueu erudit Gilbert Dahan, Barcelona era "una veritable disputa, no un judici"1". Al segle XIII, mètodes més antics de

\footnotetext{
${ }^{10}$ Vegeu Robert I. BURNS, Muslims in the Thirteenth-Century Realms of Aragon: Interaction and Reaction, "Muslims under Latin Rule, 1100-1300", ed. James M. PoweLL, Princeton, N.J., 1990, p. 101.

"Gilbert Dahan, Les intellectuels chrétiens et les juifs au Moyen Âge, París, 1990.
} 
controvèrsia van ser perfeccionats, encara que no van canviar essencialment ${ }^{12}$. La principal diferència va sorgir de la comprensió més rigorosa de la religió de l'adversari. Pel que fa als jueus, els dominics catalans estudiaven literatura rabínica tan intensament que, al cap i a la fi, podien utilizar-la per a intentar provar que el Mesies (Crist) havia arribat. El principal portaveu principal fou Ramon Martí mitjançant el seu Pugio fidei de 1278. Segons Llull, Martí tenia menys èxits en els seus debats amb els musulmans. Després tornaré a les diferències entre Llull i Martí sobre el tema dels jueus.

Els propis plantejaments de Llull cara als seus contemporanis eren originals i molt flexibles. Podia escriure tractats purament escolàstics per a la Facultat d'Arts de París, peticions curtes i efectives als reis i als papes (el que nosaltres anomenariem "projectes"), demanant-los que fessin coses concretes, i versos grollers per ajudar els estudiants a memoritzar el seu Art. Podia presentar l'Art en si mateix d'una forma poc tècnica, com en el Llibre del gentil, per a fer-lo acceptable a una audiència menys sofisticada. Les seves idees reformistes podien tenir l'aspecte d'una novel-la socio-filosòfica com Blaquerna; així, també podia variar l'èmfasi propi d'una missió al d'una croada, segons a qui s'adreçava. Probablement és un error contrastar tan clarament el primer èmfasi missioner que veiem a Blaquerna (cap el 1283) amb els darrers plans de croades. Malgrat que Llull no havia començat a escriure tractats sencers sobre aquestes abans de la pèrdua de la darrera ciutat cristiana de Palestina l'any 1291, ja les havia considerat necessàries molt abans. Llull no és inconseqüent a un nivell més profund. Mai advoca per l'ús de la força per a imposar la conversió, només per a fer possible la predicació. Innocent IV i Aquino afirmen el mateix. La diferència entre Llull i els altres sobre aquesta qüestió és que Llull havia vist la situació per ell mateix. Havia marxat al nord d'Africa a predicar als musulmans i no havia estat autoritzat a fer-ho. Així mateix, Llull era conscient de les dificultats concretes a les quals s'enfrontaven els jueus o els musulmans, àdhuc en els països cristians on eren convertits al cristianisme. Aquesta conversió significava la pèrdua de la seva pròpia comunitat (i freqüentment de totes les seves possessions) sense pertànyer encara a la societat cristiana, la qual continuava despreciant-los. Gràcies a molts documents contemporanis

\footnotetext{
${ }^{12}$ Robert ChazAN, Daggers of Faith, Thirteenth-Century Christian Missionizing and Jewish Response, Berkeley, 1989; contra Jeremy COHEN, The Friars and the Jews, The Evolution of Medieval anti-Judaism, Ithaca, N.Y., 1982.
} 
sabem que aquesta és una veritable descripció d'allò que succeïa. Per això, Llull va proposar en el Llibre de contemplació una legislació per a preservar les propietats dels conversos i castigar als cristians que es burlaven d'ells.

Les tàctiques de Llull podien variar. Les seves preferèrencies personals, definides pel que fa a les missions, podien haver estat minimitzades en societats menys pluralistes que la de Mallorca, com a la cort francesa, la qual estava molt més interessada en croades que en missions, però Llull estava sempre més preocupat per la salvació de les ànimes que per la conquesta del territori. Per a comprendre-ho, només hem de comparar-lo amb el seu contemprani Pierre Dubois, el llibre del qual, De recuperatione Terre Sancte, és una màscara transparent de l'engrandiment de la monarquia francesa.

Quan Llull s'adreçava als jueus -en el seu únic llibre sobre aquest tema-, diferia de Ramon Martí i utilitzava els textos de l'Antic Testament i no els de la literatura rabínica. Mentre que Chazan no estima aquest mètode efectiu, Gilbert Dahan el considera com un mètode totalment realista $^{13}$. Per a Dahan els jueus podien estar només influïts per les autoritats bíbliques. Nogensmenys, la majoria dels esforços polèmics de Llull estaven dirigits, como ja s'ha dit, als musulmans. Aquí -com en el Llibre del gentil-, Llull comença per confessar les veritats contingudes a l'Alcorà i alabar la bellesa de la seva llengua. Tant si s'adreçava als musulmans com als jueus utilitzava arguments derivats de la tradició platònica que compartien tots els homes cultes del seu temps, els quals incloïen l' "escala de la creació" vista com el punt de connexió entre Déu i l'home. L'Art de Llull, segons manifestava, era infal-lible perquè estava basat en l'estructura actual de la realitat. L'èmfasi que posava en els atributs divins (la Bondat, la Grandesa, l'Eternitat, i així successivament) que formen la primera i més important figura de l'Art, era propi del judaisme i de l'Islam com també del cristianisme. La forma en què eren utilitzats en l'Art era, tanmateix, particular de Llull, que l'havia adoptat de Sant Agustí i també del musulmà al-Ghazzali, una de les obres del qual havia traduit.

Si bé Llull - a diferència d'Aquino - apostava per la validesa dels raonaments per aprovar les doctrines de la Trinitat i de l'Encarnació, s'adonava que cap argument era irrefutable. Aquest punt es pot veure, per exemple, quan al final del Llibre del gentil, el Gentil (o pagà) que havia

\footnotetext{
${ }^{13}$ Vegeu les obres citades en les notes 11 y 12 , supra.
} 
escoltat les exposicions d'un jueu, un cristià, i un musulmà, decideix marxar sense dir a quina de les tres fes pretén adherir-se. Amb aquest final tan poc convencional, Llull reconeixia l'important paper desenvolupat per la Gràcia en la teologia cristiana a l'hora de perfeccionar el treball començat per la raó.

La visió apocalíptica de Llull, pel que fa a la necessitat de la reforma religiosa en la societat, està més propera a Roger Bacon que a Joachim de Fiore. Llull comparteix amb Bacon una visió de la societat centrada a l'entorn del papa, però (a diferència de Bacon) amb la participació activa de prínceps cristians. Les idees de Llull sobre l'obra misionera i les croades han de ser enteses dins de la visió general d'una cristiandat renovada. Una cristiandat renovada no podia ser egoïsticament introvertida; havia d'estar preocupada per la salvació de tothom. Llull pretenia que els seglars participessin activament en aquesta tasca. Mercaders, artesans, constructors de vaixells i mariners eren tan necessaris com cavallers i clergues. Llull sabia molt bé que era difícil mobilitzar la cristiandat d'aquesta manera. Les seves crítiques, no tan sols als prínceps i cavallers sinó també als bisbes i a la cúria papal, eren tan dures (i tan bé fundamentades) com aquelles de Robert Grossteste al concili de Lyon de l'any $1250^{14}$.

En un treball escrit l'any 1314, poc abans del darrer viatge missioner de Llull al nord d'Africa, va contestar a un suggeriment per a visitar la cúria romana i les corts dels prínceps cristians i animar-los altra vegada a recolzar la reforma dins l'església i la conversió pacífica dels no-cristians. Va escriure:

He estat a la cúria moltes vegades i he dit a molts prínceps que la fe ha de ser exaltada per tot lo món. He escrit llibres on demostrava la manera mitjancant la qual el món podia [transformar-se] en un estat de benestar, però no vaig aconseguir res $i$, a vegades, es van burlar de mi, vaig ser colpejat i em qualificaren de boig. Així que m'excuso, aniré als musulmans i veuré si puc convertir-los a la fe catòlica ${ }^{15}$.

\footnotetext{
${ }^{14} \mathrm{R}$. W. SOUTHERN, Robert Grosseteste: the Growth of an English Mind in Medieval Europe, Oxford, 1986, esp. pàgs. 276 i ss.

${ }^{15}$ Ramon LLULL, Liber de civitate mundi, ed. Johannes STÖHR, "Raimundi Lulli Opera Latina", II, Mallorca, 1960, p. 200.
} 
En aquest moment, Llull tenia més de vuitanta anys. Va escriure les seves darreres obres a Tunisia el desembre de 1315, i estan dedicades a l'emir que en aquell temps va prometre ser cristià. En una obra escrita pocs anys abans, l'any 1311 al Concili de Viena (on Llull probablement va ser un instrument eficaç per assegurar el passatge del cànon XI, amb les estipulacions per a ensenyar hebreu, àrab, i siriac als misionaris futurs, Llull va resumir la seva vida en paraules immillorables:

\footnotetext{
Jo he estat un home lligat per matrimoni, he tingut fills; era discretament ric, lasciu i mundà. Vaig deixar-ho tot de bon grat per tal de poder-me dedicar a fomentar l'honor de Déu, el bé públic i a exaltar la santa fe. Vaig aprendre l'àrab i vaig anar moltes vegades a predicar als serraïns; per causa de la fe vaig ser pres, empresonat, colpejat. He treballat quarantacinc anys per tal d'intentar de moure l'església i els prínceps cristians al bé públic. Ara sóc vell, ara sóc pobre i encara tinc el mateix propòsit, i el tindré fins a la mort si Déu voldrà ${ }^{16}$.
}

La formació de Llull a Mallorca ens ajuda sobradament a explicar les limitacions i la natura de l'èxit que, tant ell com es seus deixebles, després de la seva mort, gaudirien. A diferència de Tomàs d'Aquino, Llull mai va esdevenir portaveu oficial de cap orde religiosa. El seu rebuig a citar autoritats a la manera escolàstica acostumada fou la causa que tingués un èxit molt limitat als cercles universitaris. Mentre que Aquino prenia com punt de referència Aristòtil, Llull apostava per la tradició platònica, era descendent espiritual de Sant Agustí i Anselm i aliat de Bonaventura i Bacon. La seva adhesió a les condemnes del 1277 il-lustra la seva posició. Aquest antiaristotelisme de Llull ha estat utilitzat per a criticar el seu endarreriment respecte al temps en què va viure, però, de fet, aquesta característica el féu intel-ligible a la darrera part de l'Edat Mitjana, la qual, llevat dels restringits cercles acadèmics, rebutjava les idees aristotèliques. La mancança d'una adhesió per part de Llull a cap orde religiosa, per una banda va suposar un obstacle i, per l'altra, un avantatge. Ell va ser, durant tota la seva vida, un filòsof laic que podia entendre i penetrar en el món laic. En les seves obres en català ( $i$ en les traduccions medievals al francès, italià, $i$ en un cas a

\footnotetext{
${ }^{16}$ Llull, Disputatio Raymundi Phantastici et clerici, seu Phantasticus, ed. Michel SENELlaRT, ibid, XVI ("Corpus Christianorum, Continuatio Mediaevalis", LXXVIII), Turnhout, 1988, p. 15; la traducció és la de Lola BADIA, Disputa del clergue Pere $i$ de Ramon, el fantàstic de Ramon Llull, Bellaterra, 1985, pp. 102 i ss.
} 
l'anglès), Llull va ensenyar als laics les obligacions que provenien de l' "estat" (categoria) al que pertanyien. Aquestes son les obres catalanes que aparèixen a les biblioteques dels laics mallorquins a l'Edat Mitjana tardana ${ }^{17}$. Aquests lectors van promoure l'ensenyament lul·lià a Mallorca, Catalunya, i Itàlia els segles XV i XVI, i gràcies a ells els ideals lul·lians sobre la reforma social i eclesiàstica

s'introduiren gradualment a la societat laica.

\section{RÉSUMÉ}

Une esquisse de l'arrière-fond de la vie et des idées de Raymond Lulle (1232-1316). On voudrait faire sortir les aspects où il se trouvait d'accord avec les idées sur les missions et les croisades soutenues par les papes et les dominicains et franciscains de son époque et aussi les principales différences, dues en grande partie au fait de son éducation à Majorque (et non dans une université comme à Paris) et à son état laïque et son rang comme membre de la maison royale de Jacques II de Majorque.

\section{SUMMARY}

An attempt to sketch the background for the life and ideas of Ramon Llull (12321316) so as to bring out the ways in which he was in agreement with the ideas of the popes and the leading Dominicans and Franciscans of his time on missions and crusades and also the ways in which he differed from them. These differences were largely due to Llull's education in Majorca, rather than in a university such as Paris, and to his lay status as a former member of the royal household of James II of Majorca.

${ }^{17}$ J.N. HILlgaRTH, Readers and Books in Majorca, 1229-1550, I, París, 1991, cap. 8. Per altres referències vegeu la traducció catalana del meu llibre, Ramon Lull and Lullism in fourteenth-century France ("Oxford-Warburg Studies"), Oxford, 1971, que sortira enguany a Montserrat i contindrà una bibliografia nova. 